\title{
Genetic Diversity and Differentiation among Natural, Production, and Introduced Populations of the Narrowly Endemic Species Coreopsis leavenworthii (Asteraceae)
}

\author{
David M. Czarnecki II \\ University of Florida, IFAS, Environmental Horticulture, Gulf Coast Research and Education Center, \\ 14625 C.R. 672, Wimauma, FL 33598
}

Madhugiri Nageswara Rao

University of Florida, IFAS, Citrus Research and Education Center, 700 Experiment Station Road, Lake Alfred, FL 33850

\author{
Jeffrey G. Norcini \\ University of Florida, IFAS, Environmental Horticulture, North Florida Research and Education \\ Center, 155 Research Road, Quincy, FL 32351
}

Frederick G. Gmitter Jr.

University of Florida, IFAS, Citrus Research and Education Center, 700 Experiment Station Road, Lake Alfred, FL 33850

\author{
Zhanao Deng ${ }^{1}$ \\ University of Florida, IFAS, Environmental Horticulture, Gulf Coast Research and Education Center, \\ 14625 C.R. 672, Wimauma, FL 33598
}

\begin{abstract}
AdDitional INDEX wORDs. Leavenworth's tickseed, molecular markers, AFLP, population structure
Abstract. Seeds of Coreopsis leavenworthii Torr. \& Gray (Asteraceae) are being commercially produced but the lack of genetic diversity information has hindered growers and end users from addressing several critical issues affecting wild collection, commercial production, distribution, and the use of seeds. In this study, the genetic diversity and differentiation among natural, production, and introduced populations were analyzed at the molecular level using 320 amplified fragment length polymorphism (AFLP) markers. A high level of diversity [68.6\% average polymorphism; total genetic diversity $\left(H_{\mathrm{T}}\right)=0.309$ ] and a moderate level of genetic differentiation [total genetic diversity residing among populations $\left(G_{\mathrm{ST}}\right)=0.226 ; \Phi_{\mathrm{ST}}=0.244$; Bayesian analog of Nei's $\left.G_{\mathrm{ST}}\left(G_{\mathrm{ST}}-\mathrm{B}\right)=0.197\right]$ was detected among six natural populations - two each from northern, central, and southern Florida. Two distance-based clustering analyses, based on an individual's AFLP phenotypes or a population's allele frequencies, grouped natural populations into three clusters, concordant with our previous results from a common garden study of phenotypic variation. Clustering of populations was mostly according to their respective geographical origin within Florida. The correlation between geographical distances and pairwise $F_{\mathrm{ST}}$ values between populations was very significant $(r=0.855, P<0.0001)$. Two central Florida natural populations were divergent and grouped into separate clusters, indicating that the existence of factors other than physical distance alone were contributing to genetic isolation. Three production populations maintained a level of genetic diversity comparable to that in the natural populations and were grouped with the natural populations from which the production populations were derived, suggesting that the genetic identity of the seed origin was maintained under production practices. The genetic diversity of the introduced population was comparable to that of the source populations (central Florida natural populations), but genetic shift seems to have occurred, causing the introduced population to cluster with local (northern Florida) populations where planted. The observed genetic differentiation among natural populations may indicate a need to develop appropriate zones within Florida for preservation of genetic diversity during seed collection, increase, and distribution. This high level of population differentiation also suggests a need to collect and analyze more natural populations across Florida and from Alabama for a better understanding of the species' genetic diversity and population structure across its distribution range.
\end{abstract}

Received for publication 6 Aug. 2007. Accepted for publication 10 Jan. 2008. We thank Dr. Young A Choi and Joyce Jones for their technical assistance. This project was funded in part by the Florida Wildflower Advisory Council, by the Florida Wildflower Foundation, Inc., and by the Florida Agricultural Experiment Station.

${ }^{1}$ Corresponding author. E-mail: zdeng@ufl.edu.
Commercial production of native wildflower seeds and plants (often referred to as native forbs) has increased substantially in the United States over the past couple of decades in response to demand for native wildflowers for restoration. Seeds have been used for postfire rehabilitation of forests and 
prairies, and reclamation of mined lands (U.S. Department of the Interior, 2002). In addition, uses have been found for beautification of residences and aesthetically appealing revegetation along roadsides (Florida Dept. Transportation, 2004; Harper-Lore and Wilson, 1999; Houseal and Smith, 2000; McMahon, 2006). Increasing societal emphasis on compatibility of environments and genotypes that are suited for specific locations and resource conservation has further spurred this interest (McDonald, 2001).

In light of the mounting evidence of ecologically important phenotypic and genetic differences among populations within a species, end users of seeds of native wildflowers are increasingly requesting seeds that are more regional or site specific (Booth and Jones, 2001; Burton and Burton, 2002; Havens, 1998; Houseal and Smith, 2000; Richards et al., 1998). The concept that genetic differences exist among populations within species has long been known (Turesson, 1922). Expectations are that using site- or regionally specific seeds or plants will provide ecological and economic benefits-plantings established with such seeds or plants should be more sustainable and less expensive over the long term compared with plantings established with wildflowers derived from nonlocal or nonregional sources. Local ecosystems and climates lead to regional adaptation to those same environs. These adapted types (sometimes referred to as ecotype or source-identified seeds) are more genetically and phenotypically diverse than accessions of that species that have been subjected to a selection process (Hilker and Jurgenson, 2003). Broader genetic diversity estimates of ecotypes will facilitate the sustainability of the population by allowing plants to cope better with changing environmental conditions, as well as by reducing vulnerability of populations to unfavorable random genetic effects such as genetic drift (Burton and Burton, 2002; Havens, 1998).

Growers of regional seed types must ensure that populations are adequately sampled so as to accurately represent the genetic diversity of the original population(s). Growers must then produce seeds that are of high quality and preserve the level and composition of genetic diversity of the original, naturally occurring population (Rogers, 2004). Inadequate sampling (narrowly based genetic collection), production practices, or inappropriate distribution or use of seeds could cause loss of genetic diversity, disruption of the natural distribution of genetic diversity, and inbreeding or outbreeding depression. Breakdowns in this process could affect plant performance and survival. In addition, there could be negative impacts on species (such as insects) that have formed close associations with the native wildflowers that were planted (Ferdinandez et al., 2005; Rogers, 2004; Rogers and Montalvo, 2004). These potential negative impacts could even be more dramatic for endemic or narrowly endemic wildflower species.

Regionally specific native wildflower seeds are being produced commercially throughout the United States, with much of that production in the midwestern and western United States (Booth and Jones, 2001; Houseal and Smith, 2000; Minnesota Department of Agriculture, 1993). In the eastern United States, commercial production of native wildflower ecotype seeds is mainly in Pennsylvania and Florida. Of the 28 species of Coreopsis L. native to the United States (U.S. Department of Agriculture, 2006a), ecotype seeds of at least eight species, including Coreopsis leavenworthii, are being produced commercially in the United States, based on information from seed catalogs, internet sites, and conversations with growers. Seeds of C. leavenworthii are currently produced only in Florida. C. leavenworthii is narrowly endemic (U.S. Department of Agriculture, 2006b), with the only populations documented outside of Florida occurring in two Alabama counties (M. Nishino, pers. comm.). It is a facultative wetland species that occurs in most Florida counties (Wunderlin and Hansen, 2004), and tends to be an annual in northern Florida and a short-lived perennial in central and southern Florida (unpublished observations of the authors; N. Bissett, pers. comm.). Flowering of this obligate outcrossing species (diploid, 2n = 24; Parker, 1973; Smith, 1975) occurs mainly in late spring and summer (Clewell, 1985; Wunderlin, 1998; observations of the authors), with an extended flowering season in the southern parts of its range (Hammer, 2002).

The objectives of this study were to characterize the genetic diversity and structure of natural populations of C. leavenworthii in Florida at the molecular level, to evaluate how molecular diversity was affected by growing populations in an agronomic situation for seed or plant production, and to evaluate the effect of growing a population at another location (introduced population) on molecular diversity and genetic integrity. In a previous common garden study, we showed that natural $C$. leavenworthii populations in Florida fell into three separate clusters based on phenotypic characters, and that genetic isolation might exist in the specie's distribution within Florida (Czarnecki et al., 2007). Therefore, the focus of this study was to use amplified fragment length polymorphism (AFLP; Vos et al., 1995) as the primary tool in analyzing the species' molecular genetic diversity and in determining how results from molecular marker analyses would be related with phenotypic findings.

\section{Materials and Methods}

Plant materials. Seeds or plants were collected from three types of $C$. leavenworthii populations (natural or native, production, and introduced). Among the six natural populations were two each from northern (Jefferson County), central (Hillsborough and Osceola counties), and southern (MiamiDade County) Florida, respectively. Phenotypically, northern Florida natural populations had bipinnately compound leaves and dark-yellow ray flowers, whereas central and southern Florida natural populations had simpler, needle-like leaves, and light-yellow and dark-yellow ray flowers (Czarnecki et al., 2007). Additional information on the origin of these populations is available in Czarnecki et al. (2007). Natural populations were named using a letter corresponding to their origin $(\mathrm{N}, \mathrm{C}$, and $\mathrm{S}$ for northern, central, and southern Florida, respectively) followed by a single digit. Therefore, population N1 was the first natural population collected from northern Florida. One exception was the population S1a, which was from the same batch of seeds for population S1, but were germinated and grown in Quincy, FL, before it was shipped to Wimauma, FL, for marker analysis. Three of the four production populations were collected from commercial seed production (SP) sites, and they were designated as SP1, SP2, and SP3 populations, respectively. SP1, SP2, and SP3 populations initially originated from the same seed source in central Florida (Orange County), but seeds had been increased at different sites in Florida for various generations before collection: SP1: two generations in Alachua County; SP2: one generation in Pasco County; and SP3: four generations in Gadsden County (Czarnecki et al., 
2007). The fourth production population was from a container production $(\mathrm{CP})$ nursery, and it was designated as $\mathrm{CP} 1$. Plants originated and were grown in Hardee County, Florida (Czarnecki et al., 2007). For each of the above populations, about 300 seeds were sown in Mar. 2005, and seedlings were grown in the greenhouse in Wimauma, FL, for leaf tissue collection (Czarnecki et al., 2007). The introduced population (R1) was established on private land in DeFuniak Springs, Florida, using seeds of the SP2 population. Plants of R1 were harvested from the planting site, transplanted to containers, and grown in the greenhouse for leaf tissue collection. Young leaves were collected from plants of the above populations for DNA analyses. The number of randomly selected individuals per population ranged from 16 to 27, with an average of 22 (Table 1).

DNA Extraction. Tender leaves were collected from young plants $(\approx 3$ months old $)$ grown in the greenhouse and were used to extract genomic DNA using the cetyl trimethyl ammonium bromide (CTAB) protocol of Doyle and Doyle (1987) with minor modifications. Between 200 and $300 \mathrm{mg}$ of fresh leaf tissue was used from each plant.

AFLP MARKER ANALYSIS. AFLP markers were generated using the AFLP Plant Mapping kit (Applied Biosystems, Foster City, CA) and the manufacturer-recommended protocol with minor modifications. For each sample, $\approx 0.1 \mu \mathrm{g}$ of genomic DNA was digested with restriction enzymes EcoRI and MseI (New England Biolabs, Ipswich, MA). Adaptors were ligated to the ends of restricted DNA fragments using T4 DNA ligase (New England Biolabs). Preselective amplification was performed using EcoRI-A and MseI-C primers (Applied Biosystems) on an i-cycler Ver 3.021 (Bio-Rad, Hercules, CA). Selective amplification was performed using the EcoRI selective primers containing two selective bases and labeled with the fluorescent dye FAM (Applied Biosystems) and the MseI selective primers containing three selective bases on an $i$-cycler Ver 3.021 (Bio-Rad). Selectively amplified DNA fragments were separated on an automated DNA sequencer (ABI Prism Avant-3100 Genetic Analyzer; Applied Biosystems) through 36-cm capillary tubes, with the manufacturer-recommended running conditions. DNA fragments were displayed in the electropherograms. The size and intensity of each DNA fragment in the electropherogram was interpreted with the software GeneMapper 4.0 (Applied Biosystems) using the local Southern size-calling method. A bin panel was first automatically generated with a minimum peak intensity of 250 relative fluorescence units, and the panel was then manually corrected before being applied to the electropherogram of all the samples. All of the samples were visually checked for correct band size calling, and a relative fluorescence units threshold value of 35 was used occasionally to allow reproducibly amplified, but low-intensity fragments to be scored. Only DNA fragments between 100 basepairs (bp) and $500 \mathrm{bp}$ were scored for each sample.

DATA ANALYSIS. The binary matrix consisting of " 0 " (absence of bands) and "1" (presence of bands) for each individual plant was analyzed using population genetics computer programs to calculate the genetic diversity within populations, genetic differentiation among populations, genetic relationships among populations, and historical gene flow among populations. The levels of within-population genetic diversity were assessed using the percentage of polymorphic loci $\left[P_{\mathrm{P}}\right.$ (under a threshold value of 95\%)] and the Nei's expected heterozygosity $\left(H_{\mathrm{E}}\right)$ calculated in POPGENE (Yeh et al., 1997). POPGENE was also used to obtain an estimate of the total genetic diversity from all the populations $\left(H_{\mathrm{T}}\right)$ and the mean diversity within population $\left(H_{\mathrm{s}}\right)$. From the $H_{\mathrm{T}}$ and $H_{\mathrm{S}}$ values, the proportion of total genetic diversity residing among populations $\left(G_{\mathrm{ST}}\right)$ was calculated: $G_{\mathrm{ST}}=\left(H_{\mathrm{T}}-H_{\mathrm{S}}\right) / H_{\mathrm{T}}$, as described by Nei (1973).

Two additional methods were used to estimate the level of genetic diversity and the genetic differentiation among populations. Analysis of molecular variance (AMOVA; Excoffier et al., 1992) was performed using ARLEQUIN (Schneider et al., 2000), which partioned the total molecular variance into within- and among-populations and yielded an independent estimate $\left(\Phi_{\mathrm{ST}}\right)$ of population differentiation. A Bayesian approach (Holsinger et al., 2002; as implemented in

Table 1. Genetic diversity estimates for 11 Coreopsis leavenworthii individual populations.

\begin{tabular}{|c|c|c|c|c|c|c|}
\hline $\begin{array}{l}\text { Population } \\
\text { code }^{z}\end{array}$ & Population type (origin) & Generation & $\begin{array}{c}\text { Plants } \\
\text { surveyed (no.) }\end{array}$ & $P \mathrm{p}^{\mathrm{x}}$ & $H_{\mathrm{E}}(\mathrm{SD})^{\mathrm{x}}$ & $H_{\mathrm{B}}(\mathrm{SD})^{\mathrm{x}}$ \\
\hline $\mathrm{N} 2$ & Northern Florida (Jefferson County) & G0 & 23 & 66.9 & $0.232 \pm 0.038$ & $0.239 \pm 0.011$ \\
\hline $\mathrm{C} 3$ & Central Florida (Osceola County) & G0 & 16 & 70.6 & $0.227 \pm 0.040$ & $0.251 \pm 0.012$ \\
\hline $\mathrm{S} 1$ & Southern Florida (Miami-Dade County) & G0 & 23 & 64.7 & $0.238 \pm 0.039$ & $0.249 \pm 0.012$ \\
\hline S1a & Southern Florida (Miami-Dade County) & G0 & 20 & 70.6 & $0.236 \pm 0.038$ & $0.248 \pm 0.009$ \\
\hline SP1 & Seed production (central Florida) & G2 & 22 & 63.4 & $0.231 \pm 0.041$ & $0.236 \pm 0.014$ \\
\hline $\mathrm{SP} 2$ & Seed production (central Florida) & G1 & 27 & 66.9 & $0.248 \pm 0.039$ & $0.245 \pm 0.014$ \\
\hline SP3 & Seed production (central Florida) & G4 & 24 & 65.6 & $0.239 \pm 0.039$ & $0.243 \pm 0.013$ \\
\hline $\mathrm{R} 1$ & Introduced (originated and increased & & 26 & 68.8 & $0.250 \pm 0.039$ & $0.254 \pm 0.012$ \\
\hline
\end{tabular}

in central Florida, introduced to

northern Florida)

\footnotetext{
${ }^{\mathrm{z}}$ More information about each population were described by Czarnecki et al. (2007).

${ }^{y}$ Generation 0 (G0) refers to naturally occurring populations that had not been increased in seed or plant production; G1, G2, and G4 were populations having been increased in production for one, two, or four generations, respectively.

${ }^{x} P \mathrm{p}=$ Percentage of polymorphic loci with a $95 \%$ threshold; $H_{\mathrm{E}}=$ Nei's expected heterozygosity (genetic diversity) based on allele frequencies and assuming a Hardy-Weinberg equilibrium; $H_{\mathrm{B}}=$ expected Bayesian heterozygosity based on Squared Euclidian Distances between pairs of AFLP ${ }^{\circledR}$ haplotypes and without assuming any Hardy-Weinberg equilibrium. The $P \mathrm{p}$ and $H_{\mathrm{E}}$ statistics were calculated using POPGENE (Yeh et al., 1997), and the $H_{\mathrm{B}}$ statistics were calculated in HICKORY using its $f$-free model (Holsinger and Lewis, 2003).
} 
HICKORY, version 1.0; Holsinger and Lewis, 2003) was used to obtain another independent estimate of within-population genetic diversity $\left(H_{\mathrm{B}}\right)$ and population differentiation [the Bayesian analog of Nei's $\left.G_{\mathrm{ST}}\left(G_{\mathrm{ST}}-\mathrm{B}\right)\right]$.

The genetic relationships among populations were assessed using two statistical approaches based on an individual's AFLP phenotypes and pairwise Apostol (or simple match) genetic distances, or based on the allele frequencies within populations and the pairwise Nei's genetic distances among populations. From the Apostol distance matrix, a principal coordinate analysis (PCoA) was performed using DCENTER and EIGEN provided in NTSYSpc (Rohlf, 2005). The genetic relationships among individuals were displayed in a twodimensional plot using MXPLOT in NTSYSpc. In the second approach, pairwise genetic distances among populations were calculated using POPGENE's Nei's unbiased algorithm (1978). The output Nei's genetic distance matrices were then used in the MEGA program (Kumar et al., 2004) to generate an unweighted pair grouping method with arithmetic means (UPGMA) dendrogram of populations. Three other Coreopsis species ( $C$. grandiflora Hogg ex Sweet, $C$. verticillata L., and $C$. rosea Nutt.) were used in the analysis as outgroups to root the dendrogram. Two individuals per each of the three species were included in this analysis. Bootstrap analysis was performed in TFPGA (Miller, 1997) for 1000 replicates to test the robustness of the nodes in the dendrogram.

To assess correlation between geographical distances (in kilometers) and genetic distances, pairwise $F_{\text {ST }}$ values between populations were calculated in ARLEQUIN, and the correlation analysis was performed using PROC CORR in SAS (release 9.0 for Windows; SAS Institute, Cary, NC). Average gene flow among populations $(\mathrm{Nm})$ was obtained in POPGENE, indirectly estimated from the $G_{\mathrm{ST}}$ value, according to Wright's (1951) island model formula.

\section{Results}

AFLP PROFILES. The $C$. leavenworthii populations were initially screened using a total of 12 AFLP primer pairs in the Plant Genome Mapping kit. Primer pairs amplified from 25 to 64 DNA fragments from the $C$. leavenworthii genome. The four selective primer pairs (EcoRI TC - MseI CAA, EcoRI TC $M s e$ I CTA, EcoRI TC - MseI CTC, and EcoRI TG - MseI CAA) that produced the greatest number (between 38 and 64) of clear-cut DNA fragments were chosen to analyze all of the C. leavenworthii populations. The reproducibility of the four primer pairs was tested on 71 samples randomly selected from various populations, and it ranged from $90.3 \%$ to $100 \%$, with an average of $98.6 \%$, which is similar to the reported reproducibility of AFLP markers (Mueller and Wolfenbarger, 1999; Vos et al., 1995). Together, the four AFLP primer pairs amplified a total of 320 DNA fragments from C. leavenworthii samples.

GENETIC DIVERSITY AND DISTRIBUTION WITHIN AND AMONG NATURAL POPULATIONS. With a 95\% threshold, the percentage of polymorphic loci $\left(P_{\mathrm{P}}\right)$ at the population level ranged from 64.7 (S1) to 73.1 (N1; Table 1), with an average of 68.6. When the Hardy-Weinberg equilibrium was assumed, the Nei's genetic diversity $\left(H_{\mathrm{E}}\right)$ within each of the natural population ranged from $0.227(\mathrm{C} 3)$ to $0.255(\mathrm{~N} 1$; Table 1$)$, with an average of 0.239 . The standard deviation for these genetic diversity estimates ranged from 0.038 to 0.040 . Thus, the difference $(0.028)$ between populations in the genetic diversity estimates was smaller than the standard deviation, indicating that the six natural populations did not differ in the level of genetic diversity at the population level. The Bayesian estimates for expected heterozygosity $\left(H_{\mathrm{B}}\right.$ with the $f$ free model) ranged from $0.239 \pm 0.011$ to $0.270 \pm 0.009$ (Table 1 ), with an overall mean of $0.249 \pm 0.011$, which is slightly higher than Nei's genetic diversity estimates. The correlation between $H_{\mathrm{E}}$ and $H_{\mathrm{B}}$ was significant $(r=0.672, P=0.033)$. Thus, the natural populations from northern, central, and southern Florida showed no differences for any of the three parameters used to estimate withinpopulation genetic diversity.

The total genetic diversity $\left(H_{\mathrm{T}}\right)$ of the six natural populations was 0.309 (Table 2). The proportion of total diversity residing among populations $\left(G_{\mathrm{ST}}\right)$ was 0.226 (Table 2$)$, which indicates a moderate level of genetic differentiation among $C$. leavenworthii populations within Florida. AMOVA showed that $75.6 \%$ and $24.4 \%$ of the total molecular variance were within and among populations, respectively (Table 3 ). The estimate for population differentiation from $\operatorname{AMOVA}\left(\Phi_{\mathrm{ST}}\right)$ was 0.244 . With the $f$-free model used, the $C$. leavenworthii populations had a $G_{\mathrm{ST}}$-B of 0.197 (Table 2 ). Therefore, these three analyses showed congruent results for population differentiation in the C. leavenworthii populations.

Genetic relationships among natural populations. A PCoA was conducted on the Apostol distance matrix derived from an individual's AFLP phenotypes. Results indicated that the first two principal coordinates accounted for $6.5 \%$ and $5.7 \%$ of the total variance. Based on these coordinates, individuals from the natural populations were separated into three groups (Fig. 1). The first group consisted of individuals from two natural populations (N1 and N2) from northern Florida; the second group included individuals of the central Florida population (C2); and the third group included individuals from the southern Florida population ( $\mathrm{S} 1$ and $\mathrm{S} 1 \mathrm{a})$ and one population from central Florida (C3).

The pairwise genetic distances (Nei, 1978) between natural populations ranged from 0.027 ( $\mathrm{N} 1$ and $\mathrm{N} 2$ populations) to 0.166 (N1 and C3 populations), with a mean distance of 0.109. An UPGMA dendrogram constructed from this genetic

Table 2. Mean genetic diversity and total diversity in Coreopsis leavenworthii populations, and genetic differentiation among them.

\begin{tabular}{lccr}
\hline & $H_{\mathrm{S}}^{\mathrm{z}}$ & $H_{\mathrm{T}}^{\mathrm{z}}$ & $G_{\mathrm{ST}}^{\mathrm{z}}$ \\
\hline Among natural populations (6) & $0.239(0.253)$ & $0.309(0.315)$ & $0.226\left[0.197\left(G_{\mathrm{ST}}-\mathrm{B}\right)\right]$ \\
Among seed production populations (3) & $0.239(0.287)$ & $0.251(0.292)$ & $0.046\left[0.017\left(G_{\mathrm{ST}}-\mathrm{B}\right)\right]$ \\
Among all populations (11) & $0.239(0.249)$ & $0.308(0.308)$ & $0.226\left[0.193\left(G_{\mathrm{ST}}-\mathrm{B}\right)\right]$ \\
\hline
\end{tabular}

${ }^{\mathrm{z}} H_{\mathrm{S}}=$ Mean genetic diversity within populations; $H_{\mathrm{T}}=$ total genetic diversity from all concerning populations; $G_{\mathrm{ST}}=$ total genetic diversity residing among populations (or population differentiation); $G_{\mathrm{ST}}-\mathrm{B}=$ Bayesian analogy of $G_{\mathrm{ST}}$, total genetic diversity residing among populations or population differentiation. $H_{\mathrm{S}}, H_{\mathrm{T}}$, and $G_{\mathrm{ST}}$ values were calculated using POPGENE (Yeh et al., 1997) and HICKORY [with its $f$-free model (Holsinger and Lewis, 2003)]. Values from HICKORY were presented in the parenthesis. 
Table 3. Analysis of molecular variance partitioning of total genetic diversity within and among populations of Coreopsis leavenworthii.

\begin{tabular}{lcc}
\hline & \multicolumn{2}{c}{ Partition of total genetic diversity } \\
\cline { 2 - 3 } & $\begin{array}{c}\text { Among } \\
\text { populations (\%) }\end{array}$ & $\begin{array}{c}\text { Within } \\
\text { populations (\%) }\end{array}$ \\
\hline Natural populations (6) & 24.4 & 75.6 \\
Seed production (3) & 1.9 & 98.1 \\
All populations (11) & 22.1 & 77.9 \\
\hline
\end{tabular}

${ }^{\mathrm{z}}$ ARLEQUIN (Schneider et al., 2000) was used for this partitioning.

distance matrix clustered the six natural populations into three groups (Fig. 2), which is consistent with the PCoA of individuals of these populations (Fig. 1). Group 1 consists of two northern Florida natural populations (N1 and N2); group 2 consists of one central Florida natural population (C2); and group 3 consists of the natural southern Florida populations (S1 and S1a) and one central Florida natural population (C3). The other three Coreopsis species (C. grandiflora, C. verticillata, and C. rosea) formed clusters separate from the C. leavenworthii populations studied.

The above clustering basically corresponds to the geographical origin of populations. Genetic differentiation (based on pairwise $F_{\mathrm{ST}}$ values) between natural populations was highly correlated to the geographical distances between populations $(r=0.855, P<0.0001$; data not shown).

GENETIC DIVERSITY IN PRODUCTION POPULATIONS AND THEIR RELATIONSHIP TO NATURAL POPULATIONS. With the same threshold $(95 \%)$, the $P_{\mathrm{P}}$ at the population level ranged from 63.4 (SP1) to 72.5 (CP1; Table 1), with an average of 68.1. When

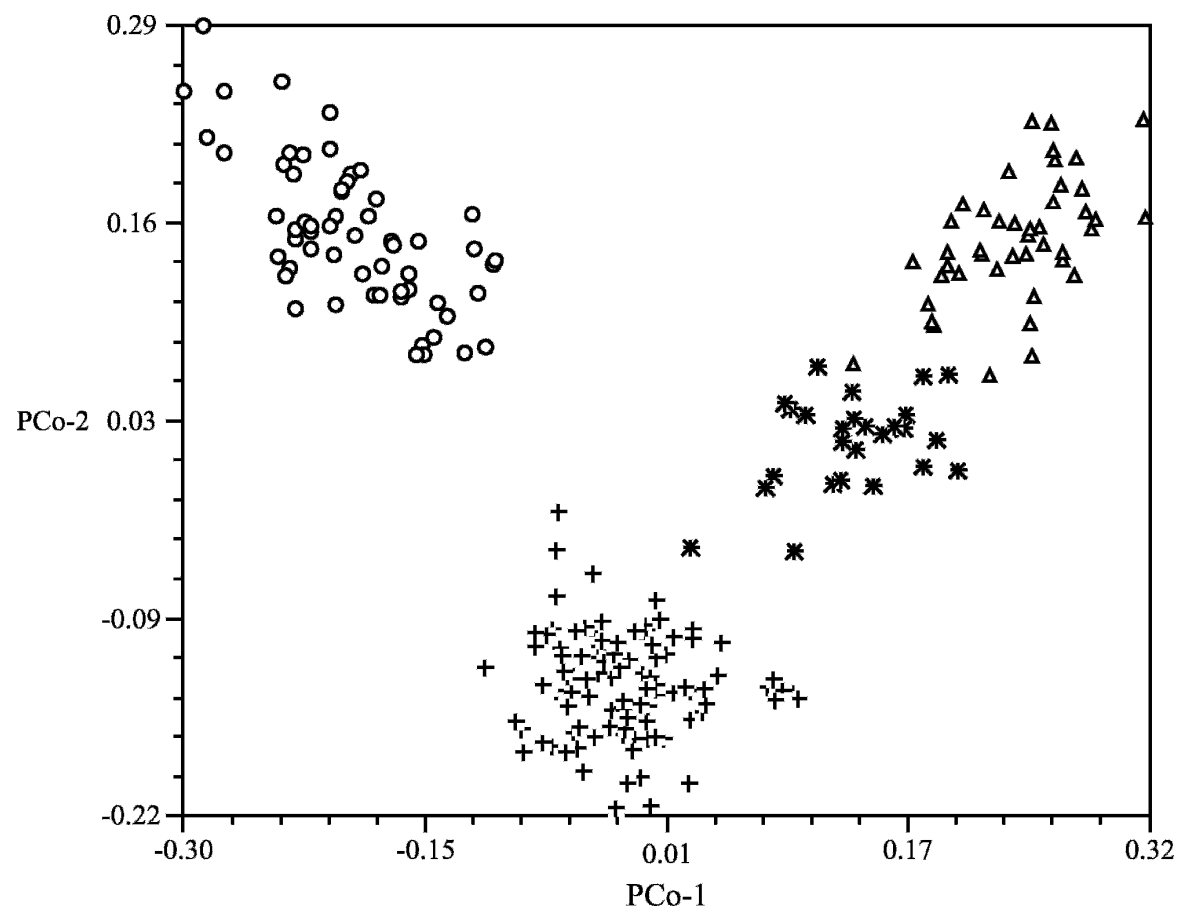

Fig. 1. Plot of the first two principal coordinates for 242 Coreopsis leavenworthii individuals [generated using NTSYSpc (Rohlf, 2005) based on the Apostol et al. (1993) genetic distance matrix and using DCENTER, EIGEN, and MXPLOT provided in NTSYSpc]. $\Delta=$ individuals from N1 and N2 populations (northern Florida); $+=$ individuals from C2, CP1, SP1, SP2, and SP3 populations (central Florida); $\mathrm{O}=$ individuals from S1, S1a (southern Florida), and the $\mathrm{C} 3$ populations (central Florida), and * = individuals from the R1 population (originated in central Florida, but introduced and planted in northern Florida). the Hardy-Weinberg equilibrium was assumed, the Nei's genetic diversity $\left(H_{\mathrm{E}}\right)$ within each of the production population was from 0.229 (CP1) to 0.248 (SP2; Table 1), with an average of 0.237 . The three SP populations had a total genetic diversity of 0.251 , with a $G_{\mathrm{ST}}$ value of 0.046 (Table 2). This $G_{\mathrm{ST}}$ value indicates little genetic differentiation among the populations. AMOVA revealed that almost all the genetic diversity (98.1\%) was within the populations, and only $1.9 \%$ among populations (Table 3). In the PCoA of an individual's pairwise Aspotol distance matrix and in the dendrogram drawn from a population's Nei's genetic distance matrix, the production populations formed a cluster with the central Florida natural population C2 (Figs. 1 and 2).

GENETIC DIVERSITY IN THE INTRODUCED POPULATION AND ITS GENETIC RELATIONSHIP TO NATURAL AND PRODUCTION POPULATIONS. The percentage of polymorphic loci, diversity estimates $H_{\mathrm{E}}$ and $H_{\mathrm{B}}$ in the $\mathrm{R} 1$ population were $68.8,0.250$, and 0.254 , respectively (Table 1 ). This level of polymorphism and genetic diversity in R1 was comparable to that in any single natural or production population studied (Table 1). In PCoA based on an individual's AFLP ${ }^{\circledR}$ phenotype and pairwise Apostol genetic distance, the individuals of the R1 population seemed to be closer to individuals from northern Florida (Fig. 1). In the UPGMA dendrogram based on a population's genetic distances, the R1 population was grouped with the northern Florida natural populations rather than with the central Florida natural populations or the production population (SP2) from which it was derived (Fig. 2).

GeNe flow AMONG POPUlations. The average gene flow $(\mathrm{Nm})$ among the natural populations was 1.71 . Within northern or southern Florida's natural populations, gene flow was much higher: 9.47 and 6.16, respectively. This high level of gene flow may be from the concerned populations being in close proximity and the outcrossing nature of $C$. leavenworthii. The three SP populations had a high level of gene flow (10.45). This seems to be understandable, considering that all the three production populations were from the same seed sources initially. Gene flow between R1 and N2, or R1 and SP2 was 5.15 and 4.66 , respectivelymore than two times greater than the average gene flow among natural populations.

\section{Discussion}

GENETIC DIVERSITY AND RELATIONSHIP AMONG NATURAL POPULATIONS. The percentage of polymorphic loci (average 68.6) and the total genetic diversity values (0.309) indicate a high level of genetic diversity in the natural populations of $C$. leavenworthii. When all populations were pooled, the percentage of polymorphic loci and the total genetic diversity were 79.1 and 0.308 , respectively. This level of genetic 

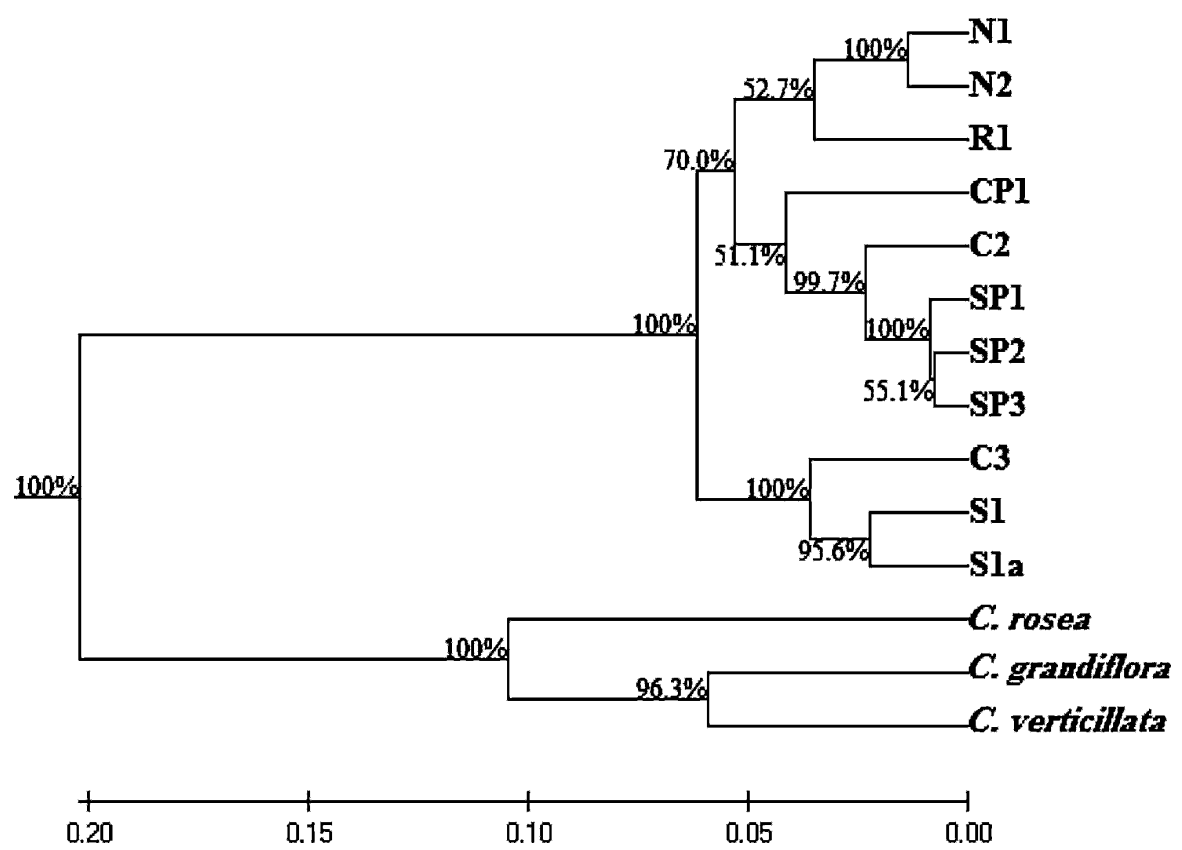

Fig. 2. Dendrogram of 11 Coreopsis leavenworthii populations based on Nei's (1978) unbiased genetic distance matrix derived from the allele frequency of 320 AFLP markers within each population. N1 and N2 = natural populations from northern Florida; $\mathrm{C} 2$ and $\mathrm{C} 3$ = natural populations from central Florida; $\mathrm{CP} 1=$ container production population originated in central Florida; $\mathrm{R} 1$ = introduced population originated in central Florida, but introduced and planted in northern Florida; S1 and S1a = natural populations from southern Florida; SP1, SP2, and SP3 $=$ SP populations originated in central Florida. Coreopsis rosea, C. grandiflora, and C. verticillata were included as outgroups. The scale indicates genetic distance between populations as clustered with UPGMA. Percentage values are bootstrap results based on 1000 replicates.

variation is greater than reported (proportion of polymorphic genes $=0.55$, total diversity $=0.187$, and diversity among populations $=0.15$ ) by Crawford et al. (1984) in their study of three natural populations from central Florida (Brevard County and Orange County, Florida, and one natural population from northern Florida (Gadsden County, Florida). They analyzed 12 isozymes encoded by a total of 20 genes, of which seven resided in the plastid genome. It remains to be determined whether the lower level of genetic diversity Crawford et al. (1984) noted among populations was from the use of different marker systems (isozyme vs. AFLP), or fewer populations, smaller geographic regions, and the substantially fewer nuclear loci sampled. Comparison of $C$. leavenworthii against other Coreopsis species in the level of molecular genetic diversity was not possible because of lack of AFLP marker analysis and data for those species. However, the results from the current AFLP work corresponded well with a previous common garden study (Czarnecki et al., 2007) in which a substantial amount of phenotypic diversity was revealed in these natural populations. Variation was observed in growth habit, survival, blooming time, and flower color and size, and variation was particularly high in leaf type (Czarnecki et al., 2007). Variation was also observed in plant resistance to powdery mildew [Golovinomyces cichoracearum (DC.) V.P. Heluta; Seijo et al., 2006] and in response to photoperiods (Z. Deng, personal observation). Based on the above results, it may be reasonable to believe that there is a substantial amount of genetic diversity in this species' natural populations, despite its being a narrowly endemic species.

Results from the four analyses (Nei's $G_{\mathrm{ST}}$, AMOVA, Bayesian, and NJ) indicated a moderate level of genetic differentiation and the existence of genetic structure among natural populations of $C$. leavenworthii. The three population groups were differentiated and the clustering of populations (Figs. 1 and 2) approximated their geographical regions. These results coincided with a principal component analysis of phenotypic variation when these populations were grown in a common garden (Czarnecki et al., 2007) in which five natural populations and three production populations were separated into three clusters (Clusters 1, 2, and 3). Cluster 1 consisted of $\mathrm{N} 1$ and $\mathrm{N} 2$ populations that possessed highly complex bipinnately compound leaves, an upright growth form, and large dark-yellow flowers. Cluster 2 consisted of the C2 natural population and SP1, SP2, and $\mathrm{SP} 3$ production populations, all originating in central Florida and with some level of leaf complexity. Cluster 3 consisted of S1 and C3 natural populations that had simple leaves and small light-yellow flowers.

The primary cause of the population differentiation in C. leavenworthii seems to be isolation by distance, as shown by the significant correlation between genetic (based on pairwise $F_{\mathrm{ST}}$ values) and geographic distances. However, one clear exception to the general isolationby-distance relationship was the $\mathrm{C} 3$ population. Geographically, $\mathrm{C} 3$ was very close to $\mathrm{C} 2$ and distant to $\mathrm{S} 1$ populations, but genetically $\mathrm{C} 3$ was very close to $\mathrm{S} 1$ and more distant to $\mathrm{C} 2$ populations. This exception suggests the existence of other factors causing the population differentiation. Coreopsis leavenworthii is facultative wetland species, but differences in soil moisture conditions may not be the cause of this isolation. The two northern Florida natural populations were in close proximity, but grew in sites where soil moisture was dissimilar (moist for N1 vs. dry for N2 populations; Czarnecki et al., 2007). Few differences were observed between N1 and N2 populations (Table 1 and Figs. 1 and 2).

Genetic drift and natural selection are the two primary evolutionary mechanisms that cause population differentiation (Hufford and Mazer, 2003). Natural selection by ecological factors will result in development of ecological adaptation or ecotypes. It remains to be determined whether the observed population differentiation resulted from any natural selection. In addition, this genetic clustering prompted us to ask whether the three clusters of populations represent three different distribution zones of genetic diversity within the natural populations. If distribution zones do exist, additional questions would be whether natural populations in each zone represent a regional ecotype, and what ecological factors contributed to this differentiation or adaptation. Development of a zoning model may be necessary to help achieve an acceptable balance between maintaining sustainability of commercial wildflower SP and maintaining a high level of genetic diversity in 
C. leavenworthii, as it has been done in the Iowa Ecotype Project (Houseal and Smith, 2000). However, distribution zones for C. leavenworthii probably would not be based solely on latitude, which is the predominant zone delimiting factor in Iowa. As Czarnecki et al. (2007) noted, natural populations C2 and $\mathrm{C} 3$ occurred at about the same latitude, but they clustered separately.

GENETIC DIVERSITY AND RELATIONSHIPS AMONG PRODUCTION POPUlation. The three SP populations (SP1, SP2, and SP3) originated from the same natural population in central Florida (Orange County), but had been in production under different climatic zones in Florida (Alachua, Pasco, and Gadsden counties; Czarnecki et al., 2007), and varied in generation (G2, G1, or G4, respectively; Table 1). Seeds from these production populations germinated more uniformly and at higher percentages than those from natural populations, and plants from the production populations were phenotypically similar and uniform in growth habit, leaf morphology, days to bloom, flower color and size, and plant survival rate in the field (Czarnecki et al., 2007). Similarly, uniformity was also evident at the molecular level as an extremely low level of genetic differentiation $\left(G_{\mathrm{ST}}=0.046\right.$, and only $1.9 \%$ of the diversity among populations) occurred among the production populations. The percentage of polymorphic loci in each of the production populations was comparable to that in each of the natural populations (63.4 to 72.5 vs. 64.7 to 73.1 in the natural populations; Table 1$)$. The molecular diversity $\left(H_{\mathrm{E}}\right)$ in each of the production populations ranged from 0.229 to 0.248 versus 0.227 to 0.255 in each of the natural populations (Table 1 ). In PCoA and clustering analysis, these production populations were grouped with the central Florida natural population $\mathrm{C} 2$. Based on these results, genetic identity (or integrity) of the seed origin can be maintained during SP of this obligate outcrossing species provided that there is no gene flow from nonproduction local populations into the production populations. The original natural population $(\mathrm{G} 0)$ from which these production populations were derived was not available for molecular marker analysis when this project was initiated. Therefore, tracking changes in genetic diversity during SP from G0 to G4 was not possible. However, the current data seem to indicate little change (or loss) of genetic diversity among the three production populations that were in different generations (SP1 population in G2, SP2 population in G1, and SP3 population in G4).

Potential CAUSES OF THE GENETIC SHIFT IN THE INTROdUCED POPUlation. In PCoA, individuals of the R1 population were closer to those from northern Florida natural populations (N1 and N2) than to those from central Florida (Fig. 1). In clustering analysis, the R1 population was grouped with the northern Florida natural populations rather than with the central Florida natural populations or the production population (SP2) from which it was derived (Fig. 2). It will be interesting to determine the cause(s) of the genetic shift in this population. One possibility might be that during the one year after being planted, a substantial amount of gene flow between the R1 population and northern Florida natural populations in the area might have occurred. Coreopsis leavenworthii is an outcrossing species and highly self-incompatible, therefore pollen-mediated gene flow among populations in close proximity is expected to occur often. Natural populations were noted in R1 population's close proximity, and a gene flow rate much higher than the average gene flow among $C$. leavenworthii populations was detected. Therefore, the suspected gene flow was very likely. Other pos- sibilities for the genetic shift might include poor adaptation of the introduced population and uneven SP from its surviving individuals. The seed source of the R1 population was from central Florida. It was unknown how well central Florida $C$. leavenworthii could perform in northern Florida.

Management implications. In summary, current analyses of genetic diversity and differentiation among natural, production, and introduced populations at the molecular level concur with our previous results based on phenotypic data (Czarnecki et al., 2007): 1) natural C. leavenworthii populations contain a high level of genetic diversity, 2) these populations are noticeably differentiated genetically, and 3) only minimal changes in diversity were detected during SP.

The results of our study may have several management implications for conservation, production, and use of C. leavenworthii. The availability of a high level of genetic diversity in the natural populations provides a rich source of genetic variation for large-scale commercial production and use of this nearly endemic species in Florida. Despite the noticeable genetic differentiation among the natural populations from northern, central, and southern Florida, all plants appeared to grow and develop similarly well when grown in a common garden in central Florida (Czarnecki et al., 2007). The results of that common garden study indicate the potential for widespread, or even statewide, use of these natural populations in Florida. However, multiyear reciprocal transplanting studies are needed to determine whether there are any home-site advantages for natural populations (for example, comparing performance of northern Florida and southern Florida population when each of these populations is planted in both locations).

Further studies will be needed to determine the cause(s) of the genetic differentiation among natural populations, and if the different groups of populations represent different regional ecotypes. The observed genetic differentiation among natural populations may indicate a need to develop appropriate zones within Florida for conserving genetic diversity/identity during mass seed collection, increase, and distribution, if this preservation becomes necessary. In addition, production populations may need to be geographically isolated (i.e., a buffer zone) from other populations that are distinctly different to maintain the genetic integrity of the production population. Gene flow can occur among populations in close proximity because $C$. leavenworthii is an obligate outcrossing species. Ideally, the geographical distance used for isolation or buffer zone should be based on species-specific gene flow information. As such information is not available for $C$. leavenworthii, a reasonable minimum isolation distance may be $0.4 \mathrm{~km}$, based on the isolation zones recommended by Houseal and Smith (2000) for native forbs.

Finally, our results and conclusions presented should be considered preliminary because we were able to sample only a limited number of natural populations (although the 11 populations sampled covered a good portion of Florida where the species is considered nearly endemic) and we were not able to compare the production populations to their original natural population (G0). To confirm our findings will require the sampling of a larger number of natural populations from within its entire distribution range, as well as the sampling of several generations of production populations including the original source population. Toward this goal, research is currently being conducted at two climatically different sites in Florida for a comprehensive assessment of potential changes in genetic 
diversity during SP of a central Florida natural population from G0 to G3. In addition, more molecular markers are being developed to further our understanding of the genetic structure in natural populations of C. leavenworthii.

\section{Literature Cited}

Apostol, B., W.C. Black, IV, B.R. Miller, P. Reiter, and B.J. Beaty. 1993. Estimation of family numbers at an oviposition site using RAPD PCR markers: Applications to the mosquito Aedesaegypti. Theor. Appl. Genet. 86:991-1000.

Booth, D.T. and T.A. Jones. 2001. Plants for ecological restoration: A foundation and a philosophy for the future. Native Plants J. 2: 12-20.

Burton, P.J. and C.M. Burton. 2002. Promoting genetic diversity in the production of large quantities of native plant seed. Ecol. Restoration 20:117-123.

Clewell, A.F. 1985. Guide to the vascular plants of the Florida panhandle. University Presses of Florida, Florida State University Press, Tallahassee, FL.

Crawford, D.J., E.B. Smith, and R.E. Pilatowski. 1984. Isozymes of Coreopsis section Calliopsis (Compositae): Genetic variation within and divergence among species. Brittonia 36:375-381.

Czarnecki, D.M., II, J.G. Norcini, and Z. Deng. 2007. Phenotypic diversity of Coreopsis leavenworthii Torr. \& Gray (Asteraceae). Native Plants J. 8:45-57.

Doyle, J.J. and J.L. Doyle. 1987. A rapid DNA isolation procedure for small quantities of fresh leaf tissue. Phytochem. Bul. 19:11-15.

Excoffier, L., P.E. Smouse, and J.M. Quattro. 1992. Analysis of molecular variance inferred from metric distances among DNA haplotypes: Application to human mitochondrial DNA restriction data. Genetics 131:479-491.

Ferdinandez, Y.S.N., B.E. Coulman, and Y. Fu. 2005. Detecting genetic changes over two generations of seed increase in an awned slender wheatgrass population using AFLP markers. Crop Sci. 45:1064-1068.

Florida Department of Transportation. 2004. Wildflower program. 23 May 2006. <http://www2.dot.state.fl.us/proceduraldocuments/ procedures/bin/650030001.pdf $>$.

Hammer, R.L. 2002. Everglades wildflowers. Globe Pequot Press, Guilford, CT.

Harper-Lore, B.L. and M. Wilson. 1999. Roadside use of native plants. Water and Ecosystems Team, Office of Natural Environ., Federal Highway Administration, Washington, DC.

Havens, K. 1998. The genetics of plant restoration: An overview and a surprise. Restoration Mgt. Notes 16:68-72.

Hilker, C.A. and J.E. Jurgenson. 2003. Genetic variation within and among two prairie plant species: A comparison of remnant populations and progeny. Proc. 18th North Amer. Prairie Conf. 18:182-188.

Holsinger, K.E. and P.O. Lewis. 2003. Hickory v1.0.4. 28 Mar. 2006. $<$ http://darwin.eeb.uconn.edu/hickory/software.html $>$.

Holsinger, K.E., P.O. Lewis, and D.K. Dey. 2002. A Bayesian approach to inferring population structure from dominant markers. Mol. Ecol. 11:1157-1164.

Houseal, G. and D. Smith. 2000. Source-identified seed: The Iowa roadside experience. Ecol. Restoration 18:173-183.

Hufford, K.M. and S.J. Mazer. 2003. Plant ecotypes: Genetic differentiation in the age of ecological restoration. Trends Ecol. Evol. 18:147-155.

Kumar, S., K. Tamara, and M. Nei. 2004. MEGA 3: Integrated software for molecular evolutionary genetics analysis and sequence alignment. Brief. Bioinform. 5:150-163.

McDonald, M.B. 2001. A philosophy of dormancy testing in native species. Seed Technol. 24:26-35.
McMahon, L.R. 2006. Understanding cultural reasons for the increase in both restoration efforts and gardening with native plants. Native Plants J. 7:31-34.

Miller, M.P. 1997. Tools for populations genetic analyses (TFPGA) 1.3: A windows program for the analysis of allozyme and molecular population genetic data. 15 Jan. 2007. <http://www.marksgenetic software.net/tfpga.htm>.

Minnesota Department of Agriculture, Market Development and Promotion Division. 1993. An assessment of Minnesota's native wildflower and grass seed market. 1993-600-1. Minnesota Department of Agriculture, Minneapolis.

Mueller, U.G. and L.L. Wolfenbarger. 1999. AFLP genotyping and fingerprinting. Trends Ecol. Evol. 14:389-394.

Nei, M. 1973. Analysis of gene diversity in subdivided populations. Proc. Natl. Acad. Sci. USA 70:3321-3323.

Nei, M. 1978. Estimation of average heterozygosity and genetic distance from a small number of individuals. Genetics 89:583-590.

Parker, H.M. 1973. A biosystematic study of section Calliopsis of Coreopsis (Compositae), University of Arkansas, Littlerock. PhD Dissertation 73-27439.

Richards, R.T., J.C. Chambers, and C. Ross. 1998. Use of native plants on federal lands: Policy and practice. J. Range Manage. 51:625-632.

Rogers, D.L. 2004. Genetic erosion: No longer just an agricultural issue. Native Plants J. 5:112-122.

Rogers, D.L. and A.M. Montalvo. 2004. Genetically appropriate choices for plant materials to maintain biological diversity. 3 Aug. 2007. <www.fs.fed.us/r2/publications/botany/plantgenetics.pdf $>$.

Rohlf, F.J. 2005. NTSYSpc numerical taxonomy and multivariate analysis system, version 2.2. Exeter Software, Setauket, NY.

Schneider, S., D. Roessli, and L. Excoffier. 2000. ARLEQUIN: A software for population genetics data analysis, version 2.000. Genetics and Biometry Laboratory, Department of Anthropology, University of Geneva, Geneva, Switzerland.

Seijo, T.E., D. Czarnecki, Z. Deng, and N.A. Peres. 2006. First report of powdery mildew caused by Golovinomyces cichoracearum on Coreopsis leavenworthii. Plant Health Progress doi:10.1094/PHP2006-1214-01-BR.

Smith, E.B. 1975. The chromosome numbers of North American Coreopsis with phyletic interpretations. Bot. Gaz. 136:78-86.

Turesson, G. 1922. The genotypical response of the plant species to the habitat. Heriditas 3:211-350.

U.S. Department of Agriculture. 2006a. The PLANTS database: Coreopsis. 8 Mar. 2007. <http://plants.usda.gov/java/name Search?mode=Scientific + Name\&keywordquery $=$ Coreopsis $>$.

U.S. Department of Agriculture. 2006b. The PLANTS database. PLANTS profile: Coreopsis leavenworthii Torr. \& Gray. 26 Nov. 2006. <http://plants.usda.gov/java/profile?symbol=COLE3>.

U.S. Department of the Interior. 2002. Report to congress: Interagency program to supply and manage native plant materials for restoration and rehabilitation on federal lands. 23 Feb. 2007. <http:// www.nps.gov/plants/npmd/Native $\% 20$ Plant $\% 20$ Materials $\% 202002 \%$ 20Report\%20To\%20Congress.pdf $>$.

Vos, P., R. Hogers, M. Bleeker, M. Reijans, T. van de Lee, M. Hornes, A. Frijters, J. Pot, J. Peleman, M. Kuiper, and M. Zabeau. 1995. AFLP: A new technique for DNA fingerprinting. Nucleic Acids Res. 23:4407-4414.

Wright, S. 1951. The genetical structure of populations. Ann. Eugen. 15:323-354

Wunderlin, R.P. 1998. Guide to the vascular plants of Florida. University Press of Florida, Gainesville, FL.

Wunderlin, R.P. and B.F. Hansen. 2004. Atlas of Florida vascular plants: Coreopsis leavenworthii. 26 Nov. 2006. $<$ http://plantatlas.usf. edu/main.asp?plantID $=1180$ >

Yeh, F.C., R.-C. Yang, T.B.J. Boyle, Z.-H. Ye, and J.X. Mao. 1997. POPGENE, the user friendly shareware for population genetic analysis. Mol. Biol. Biotechnol. Ctr., University of Alberta, Canada. 